\title{
Inappropriate restrictions on life saving technology
}

\author{
Stephen Westaby, David Taggart
}

When a patient dies it is of considerable consolation to relatives if they can be reassured that everything possible and appropriate was done. For many acute heart failure patients in the UK, this approach cannot be taken with honesty. This is because the NHS will not fund circulatory support equipment to treat cardiogenic shock in the majority of cardiac tertiary centres. Affected are $2 \%$ of 40000 cardiac surgical patients who fail to separate from cardiopulmonary bypass and around $5 \%$ of 25000 myocardial infarction patients who progress to cardiogenic shock. ${ }^{1} 2$ These disparate groups suffer ischaemia followed by reperfusion injury, then lethal but potentially recoverable myocardial stunning. ${ }^{3}$ Young patients with myocarditis or postpartum cardiomyopathy may experience a similar fate through an inflammatory process. Chronic heart failure patients suffer bouts of decompensation from which they can be rescued. At a conservative estimate these categories account for between 2000 and 3000 patients per annum in the UK.

Whereas myocardial stunning and most episodes of myocarditis will resolve over days or weeks, the immediate vicious cycle of cardiogenic shock rapidly causes metabolic derangement and death. ${ }^{4}$ Adrenergic inotropes may temporarily increase blood pressure but at the expense of tachycardia, elevated oxygen consumption and endocardial necrosis. Though widely available and supported by AHA/ACC and ESC guidelines, the intra-aortic balloon pump does not significantly increase cardiac output ( $<500 \mathrm{ml} / \mathrm{min})$. Numerous clinical trials have failed to demonstrate either reduction in infarct size or survival benefit in established cardiogenic shock. ${ }^{5-7}$ Mechanical blood pumps were developed in the 1970s, initially to support patients who could not be weaned from cardiopulmonary bypass during cardiac surgery. Early

Department of Cardiothoracic Surgery, John Radcliffe Hospital, Oxford, UK

Correspondence to Professor Stephen Westaby, Department of Cardiothoracic Surgery, John Radcliffe Hospital, Headley Way, Headington, Oxford OX3 9DU, UK; swestaby@ahf.org.uk designs sought to replicate native heart function by providing stroke volume, pulse pressure and flow up to supra-physiological levels. When it was shown that mammalian organs did not require pulsatile perfusion (just adequate flow), more efficient miniaturised implantable continuous flow pumps emerged. ${ }^{8}$

The rationale for pump deployment is indisputable. ${ }^{6}$ The failing heart beats around 120000 times per day, pumping 70001 of blood against raised afterload. For this enormous workload the dilating ventricle manifests elevated wall tension and increased oxygen consumption in the face of deteriorating myocardial perfusion. In contrast, the blood pump unloads (rests) the heart while restoring systemic and coronary blood flow. This provides the setting for parallel improvement in myocardial contractility and end organ function. For shock patients who are deteriorating inexorably, the options are mechanical circulatory support or inevitable death. As a result, prospective randomised trials of left ventricular assist device (LVAD) versus medical management are no longer acceptable. For the estimated $50 \%$ of shock survivors, clinical experience shows the long-term outlook to be good. ${ }^{12}$

In virtually all European countries and the USA, a range of circulatory support devices are utilised routinely for shock patients in cardiac centres. 9 'These range from short-term pumps deployed in the catheter laboratory to the surgically implanted permanent artificial hearts whose price tag exceeds that of a Porsche car (table 1). The less expensive temporary devices are used for rescue from cardiogenic shock and the implantable pumps to gain years of life after organ dysfunction resolves. New extracorporeal membrane oxygenator systems can be inserted percutaneously during cardiopulmonary resuscitation in any part of the hospital and used to stabilise the patient during transportation to a tertiary care cardiac facility. ${ }^{6}$ The goal of 'bridge to decision' circulatory support is to provide rapid resuscitation for shock patients who have reasonable potential for full recovery. A blood pump then sustains the patient pending functional recovery, cardiac transplantation or implantation of a longterm LVAD. ${ }^{9}{ }^{10}$ Recent information shows that even the over 70s have satisfactory quality of life and survival benefit with the implantable rotary blood pumps. ${ }^{11}$ Acute heart failure services are organised on a regional basis, enabling district hospital patients to be transferred for management by specialised multidisciplinary shock teams (cardiologist, intensivist, surgeon and perfusionist). ${ }^{12}$ For urgent resuscitation and easy transportation, extracorporeal membrane oxygenation (ECMO) circuits are deployed in minutes using percutaneously inserted cannulas, even during cardiac massage (figure 1). For outreach retrieval the district cardiologist can introduce femoral arterial and venous guide wires before the transport team arrives. ${ }^{12} 13$ ECMO immediately boosts systemic blood flow and oxygenation while decompressing the venous system. ${ }^{6}$ While the duration of ECMO is limited to days, surgically implanted temporary LVADs can be used for weeks or months. ${ }^{14}$ Direct cardiac cannulation draining blood from the left atrium or ventricular apex with pumping to the ascending aorta, avoids limb ischaemia and reduces left ventricular end diastolic pressure. Right ventricular and biventricular support can also be undertaken with surgical cannulation. ${ }^{15}$ Effective left ventricular unloading together with improved coronary perfusion form the basis for recovery of native heart function as stunning or myocardial oedema resolve. ${ }^{6}$

Full recovery of contractile function after ischaemia or myocarditis takes between 7 and 28 days. This partly explains failure of the innovative but shorter-term percutaneously inserted Impella and TandemHeart LVADs to improve survival. ${ }^{16}$ Evidence for the effectiveness of circulatory support is indisputable. In contemporary series ECMO or temporary implantable LVADs rescue around $50 \%$ of post-infarction cardiogenic shock patients and $60 \%$ or more who cannot be separated from cardiopulmonary bypass. ${ }^{14-19}$ From the Society of Thoracic Surgeons Database (USA), Hernandez et al analysed outcomes for post-cardiac surgery LVAD rescue in 5735 patients. ${ }^{2}$ They showed improving hospital survival from $38.5 \%$ to $59.2 \%$ in the 10 years between 1994 and 2004, attributing the success to safer devices, better postoperative management and earlier LVAD implantation. Similarly, data from the Inter Agency Registry for 
Mechanical Assisted Circulatory Support (USA), showed immediately life threatening shock to account for $42 \%$ of implants reported in 2009. ${ }^{18}$ Those who required only left ventricular support (the vast majority) manifest $50 \%$ survival at 6 months. For biventricular support (LVAD + RVAD), survival fell to $35 \%$. Prognosis was poor for isolated right ventricular support and use of a total artificial heart. Notably the Registry encompassed only those who received Food and Drug Administration approved pumps before 2009. It did not include patients who received the 'Levitronix Centrimag' pump which has improved outcomes throughout Europe and is now widely used in the USA. ${ }^{14} 20$ We have used this pump electively to increase the safety of very high risk cardiac surgery. ${ }^{21}$

In 2006 the National Institute for Health and Clinical Excellence (NICE) published guidance on temporary circulatory support, concluding: "limited evidence on the safety and efficacy of short-term circulatory support with LVADs as a bridge to cardiac transplantation or recovery appears adequate to support the use of this procedure provided that the normal arrangements are in place for audit and clinical governance'. ${ }^{22}$ While transplantation is in decline, much new evidence supports the use of circulatory support pending functional recovery or as a bridge to a long-term LVAD. ${ }^{10-20}$ Nevertheless the National Specialist Commissioning Group fund devices only in a few centres, intentionally constraining their use to transplant candidates or respiratory ECMO patients. During the swine flu epidemic the designated UK ECMO centres were unable to address this additional workload and their cardiac surgery came to a halt. We believe that provision of this simple intervention remains inadequate and that the Commissioning Group's standpoint that only specialised centres can manage ECMO is inaccurate and inappropriate.

Though NICE made reference to several categories of shock patient, the NHS continues to withhold circulatory support equipment from most tertiary cardiac centres, even those who perform surgery on infants and children. ${ }^{22}$ This is incomprehensible when more than half of patients who die after cardiac surgery or post-infarction shock could survive with appropriate treatment. Furthermore, it is potentially punitive to individual surgeons in a system which publishes their mortality rates. If relatively inexpensive temporary LVADs had been made available in UK cardiac surgical centres since
Table 1 Mechanical blood pumps currently used for the treatment of cardiogenic shock

\begin{tabular}{|c|c|c|c|}
\hline Device type & Pump name & Approximate duration of support & $\begin{array}{l}\text { Approximate } \\
\text { device cost per } \\
\text { intervention }\end{array}$ \\
\hline Percutaneous ECMO & $\begin{array}{l}\text { Biomedicus } \\
\text { Maquet Rotaflow } \\
\text { Levitronix Centrimag }\end{array}$ & Days $(3-28)$ & $£ 6000-10000$ \\
\hline Percutaneous LVAD & $\begin{array}{l}\text { Impella } \\
\text { Tandem heart }\end{array}$ & Days $(3-7)$ & $£ 10000-15000$ \\
\hline Temporary pulsatile VAD & $\begin{array}{l}\text { Abiomed BVS } 5000 \\
\text { Thoratec PVAD/IVAD } \\
\text { Berlin excor }\end{array}$ & Weeks $(1-26)$ & $£ 20000-25000$ \\
\hline Temporary rotary VAD* & Levitronix centrimag & Weeks $(1-12)$ & $£ 6000-8000$ \\
\hline Long-term pulsatile LVAD & Heartmate XVE & Months $(3-24)$ & $£ 60000$ \\
\hline Long-term rotary LVAD & $\begin{array}{l}\text { Micromed deBakey } \\
\text { Jarvik } 2000 \\
\text { Heartmate II } \\
\text { Heartware (HVAD) } \\
\text { Berlin incor } \\
\text { Terumo Duraheart }\end{array}$ & Years (so far up to 8 years) & $£ 60000-80000$ \\
\hline Total artificial heart & Syncardia & Months (bridge to transplant only) & $£ 100000$ \\
\hline
\end{tabular}

*Rotary refers to axial or centrifugal continuous pumping mechanisms which provide non-pulsatile blood flow. ECMO, extracorporeal membrane oxygenation; VAD, ventricular assist device (LVAD or RVAD).

the NICE guidelines, we estimate that at least 5000 lives could have been saved in the intervening 5 years. Meanwhile the deprivation/publication paradox may

understandably contribute to risk averse behaviour in surgeons to the disadvantage of sicker patients who should benefit most from cardiac surgery.

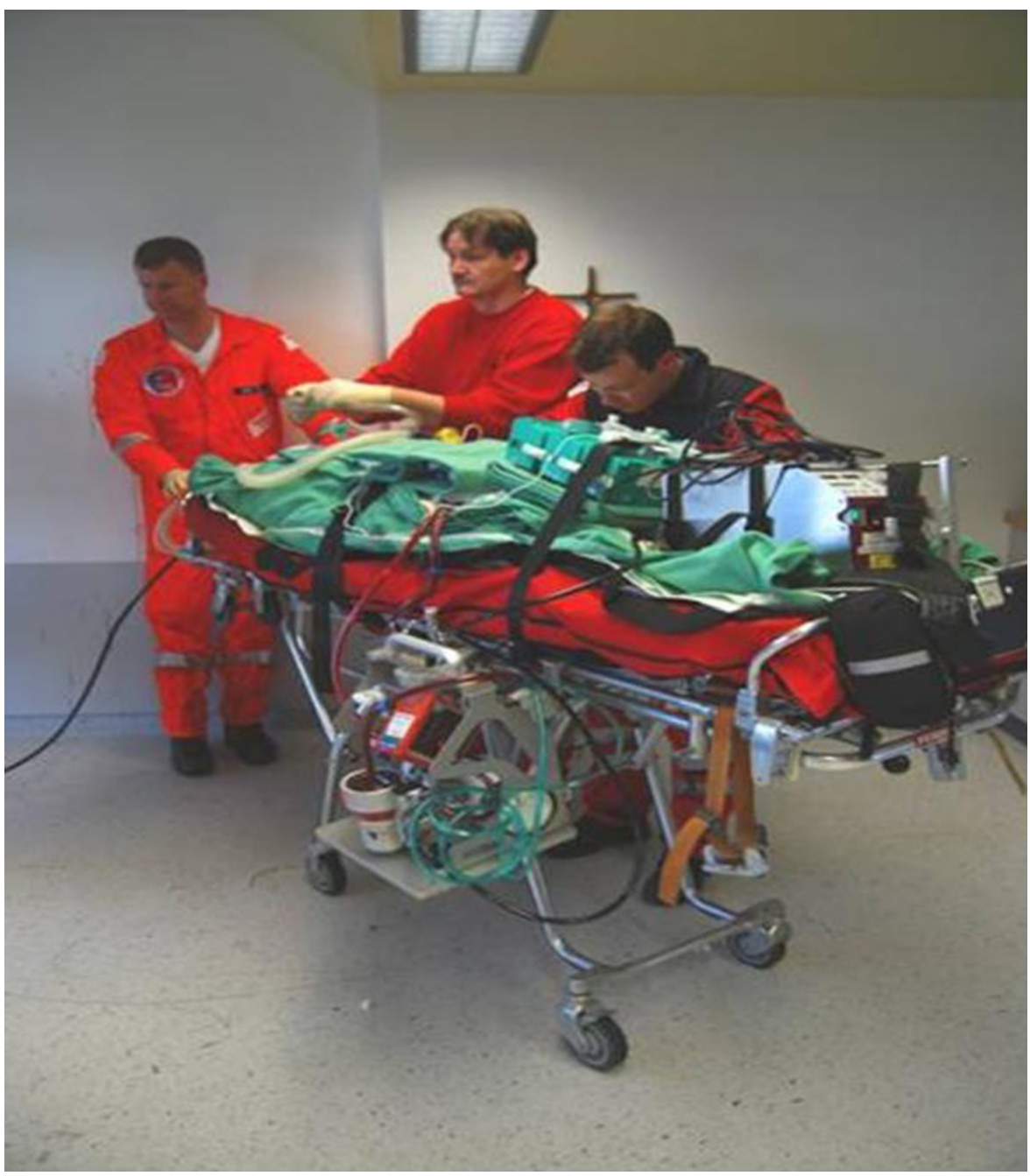

Figure 1 Transport of a cardiogenic shock patient on extracorporeal membrane oxygenation (courtesy of Prof. C Schmidt, University of Regensburg, Germany). 
Provision of circulatory support now has precedent in law. Article 2 of the European Convention on Human Rights defines 'the right to life and a positive duty on medical staff and organisations to preserve life and palliate distressing symptoms'. This ruling is pivotal when reaching decisions about life threatening illness. The General Medical Council has issued guidelines for end of life care which clearly apply to heart failure patients. ${ }^{23}$ These state that "the terminally ill must be offered high quality treatment to support them to live as well as possible until death' and that 'you should not withhold a treatment if doing so would involve significant risk for the patient and the only justification is resource constraints' (Point 39, page 27). The presumption therefore exists that all reasonable steps will be taken to prolong life if the treatment is based on contemporary evidence. Failure to treat a potentially recoverable patient could now be deemed neglectful or frankly negligent. Putting this into context, our first viral myocarditis 'bridge to recovery' patient (who benefitted from a charitably funded LVAD) has already survived for 15 years with normal left ventricular function.

In summary, the intra aortic balloon pump (IABP) must no longer be regarded as the 'ceiling' for shock treatment in contemporary UK practice. Evidence based circulatory support for heart failure should be regarded as equivalent to haemodialysis for renal impairment. If the UK is to meet the aspirations of "world class healthcare outcomes' proposed in the recent White Paper, 'Equity and excellence: liberating the NHS', then systems of care must keep pace with advances in technology. All tertiary cardiac centres must have the capacity to deal with cardiogenic shock and have access to the necessary equipment. Towards this goal a UK bioengineering group is working to develop more affordable circulatory support devices. Meanwhile the nationwide project to provide primary percutaneous angioplasty networks for myocardial infarction should now establish appropriate 'hub and spoke' shock centres in cardiac surgical units. In 2008 the cost to the NHS of providing terminal care to cancer patients (27\% of the 470000 annual UK deaths) was $£ 1.8$ billion. ${ }^{24} \mathrm{~A}$ tiny fraction of this outgoing could restore normal life to many of the patients who die annually from acute heart failure.

Contributors Both authors made a significant contribution to the content of the paper.

\section{Competing interests None.}

Provenance and peer review Not commissioned; externally peer reviewed.

Published Online First 25 May 2012

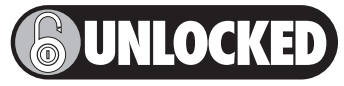

This paper is freely available online under the BMJ Journals unlocked scheme, see http://heart.bmj.com/ site/about/unlocked.xhtml.

Heart 2012;98:1117-1119.

doi:10.1136/heartjnl-2011-301365

\section{REFERENCES}

1. Hasdai D, Topol EJ, Califf RM, et al. Cardiogenic shock complicating acute coronary syndromes. Lancet 2000;356:749-56.

2. Hernandez AF, Grab JD, Gammie JS, et al. A decade of short term outcomes in post cardiac surgery ventricular assist device implantation: data from the society of thoracic surgeons' national cardiac database. Circulation 2007;116:606-12

3. Bolli R. Mechanism of myocardial stunning Circulation 1990;82:723-38.

4. Reynolds HR, Hochman JS. Cardiogenic shock: current concepts and improving outcomes. Circulation 2008;117:686-97.

5. Patel MR, Smalling RW, Thiele $H$, et al. Intra-aortic balloon counterpulsation and infarct size in patients with acute anterior myocardial infarction without shock: the CRISP AMI randomised trial. JAMA 2011:306:1329-37.

6. Westaby S, Anastasiadis K, Weiselthaler GM. Cardiogenic shock in ACS. Part 2: role of mechanical circulatory support. Nat Rev Cardiol. Published Online First: 10 January 2011. doi:10.1038/ nrcardio.2011.205

7. Sjauw KD, Engstrom AE, Vis MM, et al. A systematic review and meta-analysis of intra-aortic balloon pump therapy in ST-elevation myocardial infarction: should we change the guidelines? Eur Heart J 2009;30:459-68.

8. Saito S, Nishinaka T, Westaby S. Hemodynamics of chronic non-pulsatile flow: implications for LVAD development. Surg Clin North Am 2004;84:61-74.

9. Birks EJ. Left ventricular assist devices. Heart 2010;96:63-71.

10. Hoefer D, Ruttman E, Poelzl G, et al. Outcome evaluation of bridge to bridge concept in patients with cardiogenic shock. Ann Thorac Surg 2006; 82:28-33.

11. Adamson AN, Stahovich M, Chillcott S, et al. Clinical strategies and outcomes in advanced heart failure patients older than 70 years of age receiving the heartmate II left ventricular assist device. J Am Coll Cardiol 2011;57:2487-95.

12. El-Banayosy A, Cobaugh D, Zitterman A, et al. A multidisciplinary network to save the lives of severe persistent cardiogenic shock patients. Ann Thorac Surg 2005;80:543-7.

13. Formica F, Avalli L, Redoelli G, et al. Interhospital stabilisation of adult patients with refractory cardiogenic shock by veno-arterial extracorporeal membrane oxygenation. Int J Cardiol

2011;147:164-5.

14. Haj-Yahia S, Birks E, Amrani M, et al. Bridging patients after salvage from bridge to decision directly to transplant by means of prolonged support with the centrimag short term centrifugal pump. J Thorac Cardiovasc Surg 2009;138:227-30.

15. Anderson M, Smedira N, Samuels L, et al. Use of the $\mathrm{AB} 500^{\mathrm{TM}}$ ventricular assist device in cardiogenic shock after acute myocardial infarction. Ann Thorac Surg 2010;90:706-12

16. Cheng JM, den Uil CA, Hoeks SE, et al. Percutaneous left ventricular assist devices vs intraaortic balloon pump counterpulsation for treatment of cardiogenic shock: a meta analysis of controlled trials. Eur Heart J 2009;30:2102-8.

17. Sheu JT, Tsai TH, Lee FY, et al. Early extra corporeal membrane oxygenator-assisted primary percutaneous coronary intervention improved 30 day clinical outcomes in patients with ST segment elevation myocardial infarction complicated with profound cardiogenic shock. Crit Care Med 2010;38:1810-17.

18. Holman WL, Pae WE, Teutenberg JJ, et al. INTERMACS: interval analysis of registry data. J Am Coll Surg 2009;208:755-62.

19. Sylvin EA, Stern DR, Goldstein DJ. Mechanical support for post cardiotomy cardiogenic shock: has progress been made? J Card Surg 2010;25:442-54.

20. John R, Liao K, Lietz K, et al. Experience with the levitronix centrimag circulatory support system as bridge to decision in patients with refractory cardiogenic shock and multisystem organ failure. $J$ Thorac Cardiovasc Surg 2007;134:351-8.

21. Westaby S, Balacumaraswami L, Evans BJ, et al. Elective transfer from cardiopulmonary bypass to centrifugal blood pump support in very high risk cardiac surgery. J Thorac Cardiovasc Surg 2007:133:577-8.

22. National Institute for Health and Clinical Excellence Interventional Procedure Guidance 177 Short Term Circulatory Support With Left Ventricular Assist Devices As A Bridge To Cardiac Transplantation Or Recovery. 2006. ISBN 1-84629-233-6.

23. General Medical Council. Treatment and Care Towards The End Of Life: Good Practice In Decision Making. 2010. http://www.gmc-uk.org laccessed 11 Jan 2012).

24. National Audit Office. End Of Life Care Report 2008. Published by the National Audit office $\mathrm{HC} / 1043$ 2007-2008. ISBN:9780102954432. 